\title{
As estratégias de implantação do Sistema Único de Saúde como espaço sócio político de atuação do assistente social
}

\section{Implementation strategies of the Unique Health System as a social- political space of the social worker's performance}

\author{
Pâmela Migliorini Claudino da Silva ${ }^{1}$; Íris Fenner Bertani ${ }^{2}$
}

\begin{abstract}
Resumo
A Política de Educação Permanente em Saúde constitui uma importante estratégia para transformar o modelo de assistência e reorganizar, em nosso país, os serviços de saúde, tradicionalmente curativos. Dentro dessa perspectiva, procuramos estudar o Programa de Saúde da Família (PSF) como uma política pública. Ao ser elaborado conforme os princípios da educação permanente, o programa deverá constituir uma ação indispensável para alcançar a humanização nos serviços públicos de saúde. Partindo do pressuposto de que o PSF transformou-se em uma das mais essenciais estratégias de reorientação do modelo de atenção básica no âmbito do Sistema Único de Saúde (SUS), tratamos da necessidade da superação da hierarquia - profissional da saúde/paciente - e a importância do controle social, para que suas ações focalizem, adequadamente, os problemas. Na expectativa de romper a visão fragmentada do usuário, apontamos como fundamental a prática da intersetorialidade entre as diversas políticas públicas, no sentido de superar o caráter assistencialista/curativo da nossa saúde. Para isso, discutimos a possibilidade de inserção do assistente social na equipe de saúde do PSF por ser profissional qualificado a empreender uma política educativa de enfrentamento da questão social.

Palavras-chave: Humanização. Saúde. Programa de Saúde da Família. Educação Permanente em Saúde. Serviço Social.
\end{abstract}

\begin{abstract}
The Policy of Permanent Education in Health is an important strategy to change the assistance model and to reorganize, in our country, health services traditionally curative. Based on this perspective, it was studied the Family Health Program as a public policy that, organized according to the principles of Permanent Education, can become an indispensable action to reach the humanization in public health services. Based on the presupposition that the Family Health Program became one of the most essential strategies for the reorientation of the basic attention model in the scope of the Unique Health System, it was studied the necessity to overcome the hierarchy - health professional/patient - and the importance of the social control, so that its actions focus the problems properly. In the expectation to break off with the fragmented view of the user, it is pointed out as fundamental an intersection practice among the many public policies to overcome the assistentialist curative character of out health system. As for that, it is argued about the possibility of the Social Worker insertion in the health team of the Family Health Program, because he/she is a qualified professional to undertake an educational policy to confront the social issue.
\end{abstract}

Key words: Humanization. Health. Family health program. Permanent education in Health. Social work.

1 Assistente Social, graduada pela Faculdade de História, Direito e Serviço Social da Universidade Estadual Paulista "Júlio de Mesquita Filho", UNESP/Franca (SP). E-mail: pamelamigliorini@yahoo.com.br

2 Doutora em Serviço Social pela PUC/SP, Livre docente pela UNESP. Chefe do Departamento de Serviço Social da Faculdade de História, Direito, Serviço Social da UNESP - Campus de Franca (SP), Franca (SP). E-mail: irisfenner@ netsite.com.br. 


\section{Introdução}

Esse artigo busca apresentar as regulações legais do Sistema Único de Saúde - SUS, e os embates na sociedade atual para sua implantação definitiva, considerando os diferentes aspectos da realidade. Nessa política social pública, a apropriação do espaço pelo Serviço Social se dá expressivamente nas ações dirigidas ao que se convencionou chamar de humanização da saúde, caracterizada como uma possibilidade do Programa de Saúde da Família, por meio de iniciativas governamentais como as de Educação Permanente em Saúde. Discutir-se-á o fato de o sistema de saúde constituir "a maior política de inclusão social existente no País" (CONFERÊNCIA NACIONAL DE SAÚDE, 2004), de modo que esse sistema projeta na sociedade brasileira, um panorama de efetivação da cidadania. Historicamente, ações dirigidas à promoção humana e ao aspecto educacional, têm encontrado forte ressonância no trabalho profissional do Serviço Social e nas diretrizes definidas em seu projeto ético-político profissional.

\section{Aspectos da criação do Sistema Único de Saúde}

A atual configuração do sistema público de saúde, universal, integral e gratuito, começou a ser construído em meados da década de 1980, juntamente com o processo de redemocratização nacional. Nesse período, o país passou a enfrentar uma série de dificuldades na tentativa de equilibrar as reivindicações e pressões populares e ampliação dos serviços com a disponibilidade de recursos financeiros, os interesses do setor empresarial médico e a emergência do movimento sanitário.

$\mathrm{Na}$ época, a crescente demanda pela assistência médica fez com que vários segmentos da população (acadêmicos, profissionais e outros setores da sociedade) passassem a organizar-se e debater a necessidade da descentralização dos serviços de saúde. Esse debate culminou com a (CONFERÊNCIA NACIONAL DE SAÚDE, 1986), realizada em março de 1986, e nela foi aprovado um relatório cujas bases constituíram o projeto da Reforma Sanitária Brasileira, o que representou uma tentativa de se pôr um fim ao modelo de saúde considerado desestatizante, curativo e centralizador.

Para a Organização Pan-Americana da Saúde (OPAS), a Reforma Sanitária Brasileira foi “[...] um processo orientado para a eqüidade de suas prestações, a eficiência de sua gestão e a efetividade de suas atuações para obter a satisfação das necessidades de saúde da população". (OPAS, 1999)

Foi construído o pressuposto de que o Estado deveria responsabilizar-se pelo atendimento à saúde de toda a população, definida como "[...] resultado das condições de alimentação, habitação, educação, renda, meio-ambiente, trabalho, transporte, emprego, lazer, acesso e posse da terra e acesso a serviços de saúde [...]" (CONFERÊNCIA NACIONAL DE SAÚDE, 1987). No final da década de 1980, o Instituto Nacional de Assistência Médica da Previdência Social (INAMPS) direciona-se a uma cobertura mais universal dos serviços de saúde como, por exemplo, o fim da exigência da carteira de segurado do INAMPS para que se pudesse ter acesso a atendimentos nos hospitais conveniados a rede pública. Esse processo culminou com a instituição do Sistema Unificado e Descentralizado de Saúde SUDS, pelo decreto 94.657 de 20 de julho de 1987, num sistema de ações ainda direcionado pelo INAMPS.

A Reforma Sanitária foi fruto de lutas e mobilização dos profissionais da saúde, articulados ao movimento popular que objetivava um Estado democrático e de direito, governado pela sociedade e voltado para ela e que, ademais, se responsabilizasse pelas políticas públicas. Baseada nesse movimento, a Constituição Federal de 1988 incorpora o ideal de saúde como um direito social e dever do Estado, incluindo-a no capítulo da Seguridade, Previdência e Assistência Social (BRASIL, 1988).

Assim, institui-se na Constituição da República Federativa do Brasil, de 5 de outubro de 1988, a garantia da saúde como direito de todos e dever do Estado, (Artigo 196) e a criação definitiva do Sistema 
Único de Saúde (SUS), organizado de acordo com as seguintes diretrizes: descentralização, integralidade (com prioridade para as atividades preventivas sem prejuízo dos serviços assistenciais) e participação da comunidade, (BRASIL, 1988).

A efetivação e regulação do SUS se completam com a promulgação da Lei $n^{\circ} .8 .080$ de 19 de setembro de 1990, que dispõe acerca da promoção da saúde e a organização dos serviços, podendo-se salientar que manteve a filosofia inicial que lhe é inerente:

Artigo $3^{\circ}$. A saúde tem como fatores determinantes e condicionantes, entre outros, a alimentação, a moradia, o saneamento básico, o meio ambiente, o trabalho, a renda, a educação, o transporte, o lazer e o acesso aos bens e serviços essenciais; os níveis de saúde da população expressam a organização social e econômica do País. (CARVALHO; SANTOS, 2001, p.26)

E, na seqüência, foi promulgada a Lei $n^{\circ} .8 .142$ de 28 de dezembro de 1990, "[...] versando sobre a participação da comunidade e os mecanismos de transferência de recursos financeiros às demais instâncias de gerência, estabelecendo a previsão de remessas regulares e automáticas do governo federal".(NEGRI, 2002, p.16).

A década de 1990 é marcada pelo processo de descentralização do atendimento à saúde. No ano de 1991, dá-se início à organização dos conselhos de saúde em todos os níveis, recomendando-se como principal característica a composição paritária desses conselhos, a fim de contribuir para a efetivação da participação popular no final dessa mesma década e início do século XXI. O processo segue endossando a questão da participação popular, apesar da extrema complexidade do termo "paritário": diante do fato de que ainda atualmente a maioria da população desconhece a existência dos Conselhos, já que, "geralmente, as reuniões são de portas fechadas e não há divulgação prévia” (BETTIOL, 2003, p.66).

Em 1992, foi realizada a Conferência Nacional de Saúde, cujos principais objetivos eram a descentralização, municipalização e participação popular. Em 1996, a Conferência Nacional de Saúde, veio a consolidar a ênfase na participação dos usuários em todos os níveis do SUS, pelo aprofundamento e fortalecimento do controle social: propôs-se a articulação com outras entidades, criação de comissões intersetoriais e garantia do caráter deliberativo e fiscalizador do Conselho.

Ainda na década de 1990, foram editadas pelo Governo Federal as sucessivas Normas Operacionais Básicas (NOBs). Tratava-se de portarias do Ministério, com o objetivo de concretizar os princípios estabelecidos para o SUS até então e, também, os parâmetros da descentralização dos serviços de saúde. Na tentativa de se formar um processo contínuo, foram criadas as NOB de 1991/1992, de 1993 e de 1996, (BRASIL, 1997). Tratavam, respectivamente, do repasse do financiamento do SUS, do processo de descentralização das ações e dos serviços, estratégias para a atenção básica (como o Programa de Saúde da Família - PSF, por exemplo), e estabeleciam como política de incentivos, os modelos de atenção como o Programa de Agentes Comunitários (PAC) e o PSF. As NOBs foram complementadas por portarias, as Normas Operacionais da Assistência à Saúde (NOAS), em suas duas versões - 2001 e 2002, que, por sua vez, acrescentaram definições das responsabilidades mínimas de ação e conteúdo para a atenção básica, e de média complexidade.

Ainda em dezembro de 2000, ocorreu a Conferência Nacional de Saúde, cujo tema foi "Efetivando SUS: acesso, qualidade e humanização na atenção a Saúde, com Controle Social", numa nova tentativa de identificar e acionar a participação da sociedade (CONFERÊNCIA NACIONAL DE SAÚDE, 2002).

Conceitualmente, o controle social passou a ser entendido conforme a descrição de suas funções:

Controle Social pode ser definido como capacidade que tem a sociedade organizada (individual ou coletivamente), de intervir na gestão e na implementação de políticas públicas, interagindo com o Estado na definição de prioridades e na elaboração dos planos de ação do município, estado ou governo federal. [...] os Conselhos são uma forma democrática de controle social. (MARTINS, 2002, p.20). 
Mais recentemente, a XII Conferência Nacional de Saúde (2004), além de reafirmar as diretrizes constitucionais do SUS e as resoluções estabelecidas nas últimas quatro conferências, assegurou o fortalecimento dos valores de solidariedade e justiça social.

Fundamentada no novo contexto sócio-econômico do Brasil neste início de século XXI, a XII Conferência - cujo tema foi "Saúde: um direito de todos e dever do Estado - A Saúde que temos, o SUS que queremos" - trouxe como diferencial a discussão do processo de intersetorialidade na gestão política. Nesse processo, de acordo com uma perspectiva sistêmica, a vida do ser humano tem seus determinantes e condicionantes, que além de interdependentes, estão interligados. Com base nisso, não há mais sentido em fragmentar o cidadão criando políticas sociais diversificadas, que, muitas vezes, fracassam antes mesmo de serem implementadas, e fazem com que o cidadão deixe de ter a noção do que, realmente, é ter qualidade de vida.

Não há como persistir em práticas preventivas de saúde integradas aos anseios da população, sem estabelecer uma conexão direta com os outros setores da administração pública e a própria concepção de desenvolvimento sustentável que engloba

[...] as diretrizes de intersetorialidade e deve orientar as políticas de emprego, moradia, acesso a terra, saneamento, ambiente, educação, segurança pública, segurança alimentar e nutricional, para que, integradas às políticas de saúde, tenham por referência a saúde das populações como melhor indicador da qualidade de vida das pessoas e das coletividades. (CONFERÊNCIA NACIONAL DE SAÚDE, 2004, p.43).

Para que o sistema seja aceito e compreendido em sua importância, cabe romper, entre a população e entre os próprios profissionais da saúde, o estigma generalizado de que o SUS é somente uma política "para pobre". Seu conteúdo ultrapassa a lógica clientelista-assistencialista, porque se organiza como universal, integral, descentralizado, regionalizado e hierarquizado. Prevê em suas diretrizes, o uso da racionalidade, eficiência e eficácia, visando a participação do setor privado e da sociedade civil.
Com pouco mais de 15 anos de existência, a implantação do SUS vem ocorrendo de forma heterogênea e desigual, em razão da cultura fortemente clientelista e o ineficiente funcionamento da máquina pública no Brasil: em todos os cantos do País, deparamo-nos com governos locais com baixa capacidade de gestão. Simultaneamente, a sociedade civil demonstra-se incapaz de controlar essa ineficácia administrativa, sujeitando-se à forte manipulação que a insere em práticas de consumismo, de individualismo, de competição, enfim, num jogo político que se sobrepõe ao interesse público. Recorremos ao grande mestre Paulo Freire para embasar nossas afirmações:

[...] estas formas assistencialistas, como instrumento da manipulação, servem à conquista. Funcionam como anestésico. Distraem as massas populares quanto às causas verdadeiras de seus problemas. Fracionam as massas populares em grupos de indivíduos com a esperança de receber mais. (FREIRE, 1978, p.177)

O antídoto a esta manipulação está na organização criticamente consciente, cujo ponto de partida, por isto mesmo, não está em depositar nelas o conteúdo revolucionário, mas na problematização de sua posição no processo. Na problematização da realidade nacional e da própria manipulação. (FREIRE, 1978, p.174)

OSUS foi criado a partir da verificação da falência do modelo hospitalocêntrico, ou seja, que está centrado nos hospitais e no processo curativo de doenças.

Além da sensível melhora observada nos indicadores de morbi-mortalidade, de cobertura vacinal, e outros (NEGRI, 2002, p.15), o SUS prioriza o desenvolvimento e manutenção de programas que visam também à melhoria da qualidade de vida do brasileiro, estabelecendo estratégias para tornar as políticas exeqüíveis, desenvolvidas para áreas consideradas prioritárias, das quais destacamos algumas, como ilustração: Programa de Saúde da Família - PSF; Centro de Referência em Saúde do Trabalhador - CRST; Programa Humaniza SUS; Ações de Vigilância Epidemiológica e de Vigilância Sanitária. 
A questão da humanização no Sistema Único de Saúde

A prática do atual sistema de saúde, tal como é vivenciada pelos usuários, é bem diferente das expectativas levantadas pelas leis que o regulamentaram.

As maiores críticas ao SUS são direcionadas às verbas destinadas à saúde, que não correspondem a real demanda pelos serviços, contribuindo, conseqüentemente, para a precarização do atendimento: falta de leitos nos hospitais públicos, falta de médicos nas unidades de saúde, fila, demora no atendimento, falta de remédios nas farmácias populares e o que está em pauta no momento - a "consulta relâmpago" - feita aos usuários que relatam ficar de 3 a 5 minutos no consultório, sem que o médico ao menos os examine ${ }^{3}$. Outro desvio é a prática da "segunda porta" ou "fila dupla", quando unidades do SUS, principalmente hospitais universitários, fazem parcerias com planos de saúde.

Neste caso, os usuários dos planos recebem atenção diferenciada, "furam" a longa fila de espera do SUS de marcação de exames e consultas, passam na frente nas cirurgias e demais procedimentos, além de serem atendidos e até internados em melhores acomodações. (SALAZAR; RODRIGUES; SILVER, 2003,p.10)

Todavia, pior do que essa atitude é o conformismo com elas, num processo natural de banalização dos direitos do ser humano.

Os usuários do SUS já têm, para si, a idéia de que estão apenas recebendo um favor do Governo, um auxílio na hora da dor, melhor isto do que nada. Contudo, por seu lado, cabe à população uma parcela de responsabilidade neste estado de coisas, por naturalizar as tentativas de precarização dos recursos SUS, ao invés de exercer sua cidadania, participar da gestão da saúde pública e fazer valer sua representatividade em defesa de seus interesses.

Contudo, são os profissionais e prestadores de serviços da saúde, talvez os principais agentes da banalização da precariedade no atendimento do SUS. Além de aceitarem e conviverem passivamente com a "fila dupla", situação citada anteriormente, muitos deles descumprem e desrespeitam outros princípios do SUS: cobram taxas em dinheiro daqueles que não podem esperar a longa fila para marcação de consultas e exames; laboratórios de análises clínicas conveniados ao SUS forçam a marcação de exames para um período longo para pressionarem o pagamento de taxas, no intuito de se antecipar os exames; ou ainda, profissionais que praticam o atendimento com níveis de civilidade escalonados conforme a percepção que têm das condições sociais do usuário. Enfim, esses e outros atos acabam contribuindo para o enfraquecimento do sistema público de saúde.

Reforça esta postura o fato de que há profissionais vinculados ao SUS que não acreditam na efetividade de sua implantação como direito universal no país. São aqueles que conferem especificamente ao caráter curativo da ação clínica, o procedimento de "curar o paciente". Assim é que, de um lado, preconiza-se a implantação de programas como o PSF, que visam a uma relação maior com a comunidade, a análise do indivíduo como um todo, dentro de um contexto sócio-político e cultural, e o trabalho em equipe para a prevenção e promoção da saúde num atendimento mais humanizado. E, em uma perspectiva contrária, cabe citar a tentativa de estabelecer que toda a atividade que se possa e se queira fazer, em benefício da saúde física e psicológica do homem, tem de ser inicialmente autorizada e fiscalizada pela classe médica (Projetolei de $n^{\circ} 025 / 2002$, conhecido como "Projeto do Ato Médico"). Esse desencontro de afirmações guarda, em seu interior, a própria dificuldade de se buscar estabelecer uma face simplificada às complexidades do processo da saúde coletiva/individual.

Podemos afirmar que a valorização do direito à saúde também depende, em certos aspectos, da conscientização da classe média - que, embora achatada pelas atuais configurações do mercado de

Baseado em artigo de (MATIUZO; GALLO, 2004) retirado do caderno Folha Ribeirão do Jornal Folha de São Paulo, maio de 2004. 
trabalho e escassas oportunidades de bons salários, vincula-se aos planos de assistência privada ou seguro de saúde, mesmo com sacrifícios em seu orçamento doméstico. Com isso, paga duplamente, como contribuinte e como voluntário, pelo serviço insatisfatório de atenção à saúde que recebe em qualquer das duas instâncias.

A luta pelo direito à saúde, como um direito das pessoas pobres, valoriza a saúde apenas como um direito que deve ser satisfeito no campo da assistência social, esvaziando-o de seu conteúdo de direito social e individual a ser garantido pelo poder público a qualquer cidadão. (CARVALHO; SANTOS, 2001, p.45).

É quando a própria sociedade contribui para uma desresponsabilização cada vez maior do Estado perante a garantia de todos os direitos sociais inscritos na Constituição Federal.

Assistimos a um desmonte cada vez mais intenso do Estado, por meio de privatização dos serviços públicos, quando não a terceirização destes, num processo de arrochamento dos recursos destinados às políticas públicas em prol dos ditames de grandes instituições financeiras e representantes do capital internacional. Enquanto isso, a lógica do consumismo acelerado que tomou conta do mundo nas últimas décadas, também prevalece em nossa sociedade, e faz com que seja reproduzida em enorme anseio pela compra de educação, saúde, plano de previdência, segurança, lazer, ou seja, dos direitos que, agora, se transformaram em mercadoria. Podemos recorrer mais uma vez a Carvalho e Santos (2001, p.46), ao se referirem ao assunto, quando afirmam que "é grande a diferença entre lutar por um direito sentido e tido como seu e lutar por um direito devido apenas ao pobre, de forma piedosa".

Verifica-se um controle social frágil e desestimulado dos processos de gestão do SUS, a formação de profissionais, até agora sob influência centralizadora, curativa e distante do debate acerca da atual conjuntura e de uma participação mais efetiva na formulação da política pública de saúde, o desrespeito aos direitos dos usuários e de um sistema público de saúde ainda burocratizado e verticalizado.
Diante desse impasse, foi recriada uma estratégia antiga de valorização da solidariedade aos doentes, agora repaginada como uma política nacional compromissada com a humanização das ações de efetivação de programas e projetos de todas as instâncias do SUS. O Ministério da Saúde criou, então, a Política Nacional de Humanização/Humaniza SUS (BRASIL, 2004), em nível hospitalar. A qualidade dos serviços é tida como um dos fatores da humanização. Além disso, são priorizados o acolhimento e o atendimento aos usuários, o trabalho dos profissionais, a lógica de gerência e gestão, a criação de uma cultura de humanização por meio da sensibilização da administração hospitalar e a constituição de grupos de trabalho que visam a proporcionar ao paciente um ambiente de conforto e bem-estar.

Numa aproximação mais ampla e aprofundada da própria contextualização da Política Nacional de Humanização, afastamo-nos da assistência curativa hospitalar para nos determos, neste estudo, na análise do Programa de Saúde da Família como principal método de efetivação da prática humanizadora. $\mathrm{O}$ objetivo primordial do PSF é a prevenção que, se for pensada na totalidade de sua proposta de intervenção, já se constitui em um aspecto da humanização. A nosso ver, a implantação de uma revisão de procedimentos de natureza comportamental passa, necessariamente, pela estratégia educativa. A observação de situações em que sobressaem a falta de respeito, de atenção, de solidariedade e de valorização do ser humano diante da situação de doença é nosso ponto de partida para as reflexões que ora se seguem no desenvolvimento deste ensaio.

Desde sua criação, o Sistema Único de Saúde (SUS) vem enfrentando forte crítica quanto à sua estrutura administrativa e financeira, e políticas de ação desenvolvidas. Tais críticas têm sido, nos últimos anos, transferidas ao precário atendimento direto dos usuários, ou seja, às dificuldades na capacitação e gestão de recursos humanos.

É o que nos leva a enfatizar, a partir da implantação da Política Nacional de Educação Permanente em Saúde, o Programa de Saúde da Família (PSF), como estratégia principal de ação interdisciplinar para se 
garantir um atendimento mais humanizado na saúde pública. A construção do conhecimento acerca da "Educação Permanente como estratégia para humanização na saúde" fundamenta-se na análise do PSF como espaço para seu desenvolvimento.

\section{O Programa de Saúde da Família}

$\mathrm{Na}$ tentativa de concretizar os princípios estabelecidos pelo SUS, foi criado em 1991 o Programa de Agentes Comunitários de Saúde (PACS), como uma forma de efetivar "[...] pela primeira vez a atenção à família e não à pessoa". (SOUZA, 2002, p.223).

Considerando a saúde do ser humano e a prevenção de suas doenças ligadas a fatores muito amplos e complexos como condições socioeconômicas, hábitos de higiene, hábitos de alimentação, emprego, moradia adequada, etc., tornase necessária a recomendação da intervenção nas próprias condições gerais de vida e utilização dos recursos comunitários.

O objetivo central do PACS, de acordo com Souza (2002), é incentivar uma atitude pró-ativa em saúde pública, em que o profissional em lugar de esperar a demanda doente 'chegar' para intervir, passava a agir sobre ela preventivamente.

A execução do PACS, a princípio, direcionavase ao enfrentamento dos altos índices de mortalidade infantil e materna, verificados na Região Nordeste. Em 1992, o programa se expande para a região Norte com o propósito de conter a cólera que surgia no país.

Apesar de as redes de serviços de saúde continuarem desarticuladas, o PACS contribuiu para fixar trabalhadores de saúde - especialmente enfermeiros - nos municípios da região Norte e Nordeste, nas quais se concentrava o maior índice de população pobre do país, ou seja, a que se encontrava mais vulnerável aos riscos de adoecer e morrer.

Todavia, ainda segundo Souza (2002, p.224), era necessário "[...] criar instrumentos ou intervenções para a ruptura com o modelo de atenção tradicional [...]", centrado na doença. Este era configurado como curativo e concentrador das ações e recursos disponíveis para uma medicina de alto custo que, ao ser exercida de forma verticalizada, tornava-se acessível apenas a uma parcela restrita da população.

Desse modo, é criado em março de 1994 o Programa de Saúde da Família (PSF) como uma estratégia de extensão do PACS. Esse programa era mais estruturado, e a ele foram incorporados recursos humanos e tecnológicos necessários para garantir a descentralização e universalidade dos serviços prestados, e deveria estender ações básicas de saúde para toda a comunidade brasileira. O PSF deveria "promover a reorganização da prática de assistência com novos critérios de aproximação e de atenção continuada, resolutiva e pautada pelos princípios da promoção de saúde" (SOUZA, 2002, p.224).

Os projetos de cooperação técnica na área da Atenção Básica visam, principalmente, à estruturação do nível de atenção primária no Brasil pela expansão da estratégia Saúde da Família, e isso contribui para transformar o modelo de assistência e para reorganizar os serviços de saúde, tradicionalmente curativos.

O Programa de Saúde da Família, agora com uma década de implantação no Brasil, cobre mais de $80 \%$ dos municípios do país e inclui cerca de 190 mil agentes comunitários e mais de 20 mil equipes de saúde da família que acompanham, regularmente, mais de 60 milhões de pessoas ${ }^{4}$. É desenvolvido com enfoque comunitário e de educação para a saúde, dando prioridade à prevenção e ao atendimento de todos os membros da família, de modo que seja dado transformar o comportamento, as práticas e a organização dos serviços. Transformou-se em uma das mais importantes estratégias de reorientação do modelo de atenção básica no âmbito do Sistema Único de Saúde, possibilitando que as ações focalizem, adequadamente, os problemas. Amplia o acesso da população aos serviços de saúde e aumenta a cobertura assistencial, em especial nas áreas de

${ }^{4}$ Informações retiradas do site http://www.unesco.org.br acesso em 5 de maio de 2005. 
baixa renda, nas quais a oferta é mais escassa. O PSF, enquanto estratégia de saúde, busca uma transformação que possa promover a eqüidade, humanizar $\mathrm{o}$ atendimento e reorganizar a referência para os serviços de maior complexidade.

Além das mudanças estruturais no modelo de assistência, de forma objetiva e pragmática, o PSF visa a proporcionar melhorias nas condições de saúde da população: aumentar a cobertura vacinal, reduzir as internações por causas previsíveis, diminuir a mortalidade infantil, materna e geral, aumentando, dessa forma, a satisfação da população atendida.

O novo modelo elege como espaço estratégico o domicílio e a comunidade, valorizando várias dimensões que se perderam na centralização dos serviços, como a história e a cultura da comunidade e tudo mais que torna significativa uma relação social. (MARTINS, 2002, p.24).

O modelo de trabalho priorizado pelo PSF é o interdisciplinar, numa busca permanente de comunicação e troca entre os saberes específicos dos profissionais da equipe e o saber popular do Agente Comunitário e da população em geral. Com isso, são estabelecidos vínculos de responsabilidade com a comunidade.

Essa equipe precisa estar habilitada para desenvolver "ações de promoção, proteção, diagnóstico precoce, tratamento e reabilitação que são características do nível primário de atendimento à saúde", tendo como campos de intervenção o indivíduo, a família, o ambulatório, a comunidade e o meio ambiente. (MARTINS, 2002, p.7)

Uma das diretrizes de trabalho do PSF é promover, com a equipe de saúde da família, atividades com grupos nas diferentes fases da vida conforme a demanda da população local. Dentre as mais freqüentes estão: Saúde da Mulher; Saúde da Criança; Ações de Vigilância Epidemiológica; Atenção Domiciliar; Atividades Educativas para Idosos; Adolescentes; Hipertensos; Diabéticos; Desnutridos.

Há, contudo, muitos fatores que interferem na implantação do PSF, e criam uma enorme dificuldade de implantação de sua lógica de funcionamento. Entre eles, ressalta-se a aceitação do princípio de levar a saúde para mais próximo do cotidiano da família, integrar indivíduo e comunidade, percebendo-o como um todo, inserido num contexto que interinfluencia todos os aspectos de sua vida.

Para a superação dessas dificuldades e o atendimento das demandas, está prevista a realização de cursos de capacitação para os profissionais do PSF, com o objetivo de mudar a visão dos trabalhadores da saúde e usuários em relação a uma política de saúde curativa, especialista e minimista.

Entretanto, pensar um projeto de humanização a partir do PSF não se restringe à mudança de hábitos, formas de aprendizado e atuação dos trabalhadores da saúde. Esse processo inicia pela qualificação dos profissionais da equipe do PSF e pela sua valorização enquanto pessoas capacitadas e comprometidas com o seu trabalho e com a população que atendem. Há necessidade de se primar pelo respeito, pela atenção, pela solidariedade, pelo atendimento sem indiferença e sem diferenças e pela valorização das pessoas como subsídios básicos para posteriores ações de humanização que não se restrinjam somente ao PSF.

A humanização dos serviços públicos de saúde também perpassa pelo interesse da população em participar, conhecer essa questão que é sua de direito. Cabe-lhe tomar ciência do que está sendo construído e implantado na sua comunidade, no seu município, enfim, de exercer sua cidadania.

O PSF constitui uma verdadeira política de humanização na saúde, a começar pelos seus objetivos: a prevenção de doenças e a promoção da saúde. Com o programa, os profissionais, em contato direto com os moradores de cada região e suas famílias, podem orientá-los com relação a uma série de cuidados com a saúde, analisar a situação socioeconômica, acompanhá-los em tratamentos mais complexos, enfim, tratá-los como verdadeiros cidadãos, respeitando seus direitos. A equipe de saúde do PSF é sensibilizada a perceber cada grupo familiar como um todo pertencente a um contexto que influi no comportamento e modo de viver de toda a comunidade.

Buscou-se realizar essas propostas e visou-se à qualificação dos trabalhadores da saúde, bem como 
a capacitação dos profissionais de outras áreas, a fim de dar início ao processo de intersetorialidade com as demais políticas públicas. Por isso, o Governo Federal instituiu em 13 de fevereiro de 2004, Portaria nº. 198/Gabinete do Ministro/Ministério da Saúde (BRASIL, 2004), a Política Nacional de Educação Permanente em Saúde como estratégia do Sistema Único de Saúde para a formação e o desenvolvimento de trabalhadores para o referido setor (BRASIL, 2005).

A Educação Permanente, nesse contexto, passa a ser aqui discutida como estratégia interdisciplinar para a humanização no atendimento dos serviços públicos de saúde, constituindo, dessa forma, um dos expedientes mais importantes para se iniciar um processo de luta pela inclusão social, pela cidadania plena e construção de uma sociedade mais justa. É aspecto que torna importante a presença atuante do assistente social na composição da equipe com os demais profissionais, já que se possibilitam alternativas para a melhoria das condições sociais da população e, o mais importante, fazê-la sentir-se responsável por serviços públicos de qualidade.

Portanto, pari passu à participação do assistente social na equipe, há necessidade de que sejam priorizados os programas preventivos incentivados pelo Governo Federal, principalmente os voltados à atenção básica e ações preventivas de saúde como o Programa de Saúde da Família, Programa de Agentes Comunitários de Saúde e, mais recentemente, a Política de Educação Permanente em Saúde.

Considerando a educação como estratégia para superação do atraso social, da alienação política e das práticas assistencialistas como instrumentos de manipulação, foi instituída no país uma forma de articular a política de educação com o desenvolvimento do Sistema Único de Saúde.

\section{O PSF como espaço para o desenvolvimento da Política de Educação Permanente}

Baseados nos preceitos que fundamentam a Política Nacional de Educação Permanente, podemos considerá-la a partir de uma perspectiva que privilegia a vigilância à saúde como uma questão social, econômica, política e, sobretudo, um direito de todo cidadão. (BETTIOL, 2003, p.142), Com isso, ela passa a constituir uma estratégia interdisciplinar para alcançar práticas mais humanizadoras nos serviços de saúde.

No tocante à viabilização da estratégia de saúde da família, foi transferida a instâncias denominadas Pólos de Educação Permanente, a atuação na perspectiva de gestão da promoção, formação e o desenvolvimento das equipes de saúde nos espaços locais e microrregionais. Esse processo se consolidaria na medida em que fossem colocadas em prática ações como acolhimento, vínculo entre usuários e equipes, responsabilização e desenvolvimento da autonomia dos usuários por meio da integralidade da atenção à saúde. Essa integralidade é compreendida como a clínica ampliada, o conhecimento sobre a realidade, o trabalho em equipe interdisciplinar e ação intersetorial com os aspectos epidemiológicos, econômicos, culturais e demográficos da população de cada microrregião.

As equipes, para corresponder a essas responsabilidades, necessitam organizar-se para atuar num processo permanente de qualificação que envolva articulação e o diálogo entre si, com outros profissionais da saúde, usuários e gestor de saúde. A discussão a ser estabelecida com esses parceiros enfocaria os programas, grupos sócio-educativos e o sistema de saúde, as novidades tecnológicas em tratamento e prevenção de doenças, orientação acerca da clínica ampliada num constante sistema de análise e problematização.

No entanto, tal política voltada para a construção de estratégias para a humanização nos serviços públicos de saúde não se restringe a ações intersetoriais com a educação em processos de mudança na graduação, nas residências, na pósgraduação e na educação técnica dos profissionais de saúde. Ela está, principalmente, direcionada ao estímulo do controle social, da participação popular.

Porém, devido à forte influência de práticas governistas de administrações públicas de caráter paternalista/assistencialista, o trabalho de despertar 
uma consciência crítica adquire uma maior complexidade. Numa visão simplista, podemos afirmar que uma parte da população acomodou-se à situação e, ainda, acredita receber favores do governo, enquanto a outra permanece neutra temendo represálias políticas daqueles que utilizam o poder de governar para solucionar impasses pessoais ou de familiares.

O PSF torna-se, assim, a porta de entrada para o desenvolvimento de trabalhos que objetivem o despertar de uma consciência crítica na população. Nas palavras de Spozati, temos uma reflexão que demonstra a visão dominante da participação popular em nossa sociedade, ao se referir que " $[\ldots]$ o povo vira uma presença que preenche espaços, mas é congelada em sua capacidade de autoria histórica". (SPOSATI; LOBO, 1992, p.373).

A população, para exercer o controle do uso de verbas públicas a ela destinadas, precisa contar com elementos que o permitam entender, conhecer, interagir, planejar, executar, monitorar e avaliar as ações e políticas públicas do município. Ninguém mais apto do que os próprios moradores para avaliar as dificuldades dos seus bairros, participar dos grupos sócioeducativos na unidade de saúde, formular propostas, enfim, libertar-se da mera condição de massa de manobra política e transformar-se em sujeitos de sua própria história, cidadãos críticos que superem o conformismo e lutem pela efetivação de seus direitos.

A participação pode iniciar-se por ações simples como a integração com os grupos e programas desenvolvidos na unidade de saúde, palestras, por meio de sugestões acerca de atividades complementares, conhecendo o trabalho da equipe até alcançar o âmbito geral, aquilo que é discutido nas reuniões do Conselho Municipal de Saúde.

A população tem o direito de participar das reuniões, acompanhar o desenvolvimento dos programas e atividades na saúde e o direcionamento das verbas vindas dos Governos Federal e Estadual, pois "O SUS é a certeza de que nos municípios, a comunidade que vivencia de perto os problemas, sabe também encontrar as melhores respostas". (BRASIL, 1993, p. 5)
A criação dos Conselhos de Saúde não é apenas uma exigência legal. É a garantia de que a sociedade deixe de ser apenas usuária dos serviços para se transformar, efetivamente, em agente de mudança (BRASIL, 1993, p. 5).

A proposta para um atendimento mais humanizado no PSF teria continuidade, sempre que fosse dado capacitar, por meio da educação permanente, os diferentes profissionais e movimentos populares, para que estes possam ter uma visão de totalidade, seja de um determinado indivíduo ou de determinada situação e compreender como são implementadas as políticas sociais a partir dos objetivos do SUS, conhecer leis e princípios que o fundamentam. Haveria, assim, a possibilidade de maior integração na efetivação do SUS enquanto política pública, além de oferecer subsídios para a prática da intersetorialidade.

O próximo passo dessa proposta de humanização do PSF é direcionado à elaboração de políticas relativas à educação permanente dos trabalhadores de saúde. Com base no artigo de Ceccim (2004), essa noção fragmentada de saberes termina por se impor aos profissionais, aos serviços e à sociedade, e temos como resultado "a expropriação dos demais saberes e a anulação das realidades locais em nome do conhecimento/da expertise". (CECCIM, 2004, p.163).

A partir dessas referências propõem "políticas específicas" ou, como tradicionalmente acontece, "programas de ação" ou "ações programáticas", quase sempre assentadas na assistência individual, em particular sobre o atendimento médico, ou em macropolíticas de vigilância à saúde. (CECCIM, 2004.).

Em geral, as áreas, os intelectuais especialistas e os consultores trabalham com dados gerais que possibilitam identificar a existência dos problemas e sugerir sua explicação, mas não permitem compreender sua singularidade, sua vigência subjetiva, suas conexões de sentido local. (CECCIM, 2004, p.164).

Essa forma de apropriação do conhecimento e das práticas limita o processo da intersetorialidade. Há que se desconstruir a compreensão segmentada da realidade assumindo um entendimento global das 
questões que devem constituir-se em objeto de ação. Essa perspectiva limitadora tem dificultado o entendimento de que a saúde deve interagir com as demais políticas sociais e econômicas. Além do mais, contraria o conceito de saúde adotado pelo SUS, que a determina como resultante da correlação entre toda a complexidade de fatores que norteiam a vida de um ser humano.

Por isso,

Para produzir mudanças de práticas de gestão e de atenção, é fundamental que sejamos capazes de dialogar com as práticas e concepções vigentes, que sejamos capazes de problematizá-las [...] e de construir novos pactos de convivência e práticas, que aproximem os serviços de saúde dos conceitos de atenção integral, humanizada e de qualidade, da eqüidade e dos demais marcos dos processos de reforma do sistema brasileiro de saúde [...]. (CECCIM, 2004, p.164).

Para uma prática humanizadora na saúde, é imprescindível que tomemos o indivíduo como integrante de uma comunidade, contextualizada em meio a questões políticas, econômicas e culturais que o influenciam de algum modo. A partir de uma análise das experiências locais é que entenderemos que ações devem ser planejadas "[...] em redes/cadeia [...] com integração entre formação, desenvolvimento docente, mudanças na gestão e nas práticas de atenção à saúde [...]", de acordo com Ceccim (2004, p.165).

E, a partir dessa análise, propomos o Programa de Saúde da Família, como uma estratégia dirigida, simultaneamente, para a execução da Política Nacional de Educação Permanente em Saúde e a humanização dos serviços de saúde em nível microssocial. Como estratégia inicial, pensaríamos em esclarecer a população acerca do que, realmente, é o Programa de Saúde da Família, para, posteriormente, romper com a visão tradicionalista de que o atendimento médico deve ser feito por um especialista, que receite remédios e exames num sistema de trabalho curativo e centralizador.

Além disso, buscaríamos desenvolver uma metodologia para contribuir com o rompimento da visão minimista do PSF e da atenção exclusiva do médico nos cuidados com a saúde, que pode levar ao erro de perpetuarmos a figura santificada do "médico-messias", responsabilizando-o como único agente curador de todas as patologias, independente do processo sociocultural e econômico a que está submetida a população de uma comunidade. "Tal verificação pode ser verificada pelo próprio modelo de pensar o processo de saúde/doença que [...] desde sua origem tem-se centralizado na figura do médico." (BETTIOL, 2003, p.80). A importância da intervenção clínica médica dá-se em sua área específica de atenção, a ser beneficiada por medidas sanitárias e epidemiológicas, locais de controle da própria comunidade, completando ações de saúde pública.

Para a introdução desse novo paradigma, tornase imprescindível a criação e desenvolvimento de projetos que priorizem a instrução da população quanto aos princípios e objetivos do PSF. Há, também, a necessidade de priorizar os serviços de informação à população e os métodos mais imediatos para sanar dúvidas, desde questões simples de saúde do cotidiano da família, a cuidados pessoais que possam ser considerados mais constrangedores de serem abordados coletivamente. Isso é o que torna humanizadas as informações claras, objetivas, completas e compreensíveis acerca de qualquer dúvida em relação a tratamento, medicação, exames, consultas e outros procedimentos.

O usuário do sistema de saúde tem ainda o direito de ser informado dos critérios de seleção quando houver limitação de atendimento para os grupos sócioeducativos e outros serviços de saúde promovidos pela unidade do PSF. Nessa cultura da humanização, não há espaço para qualquer tipo de discriminação ou restrição de atendimento por questões de orientação sexual, gênero, idade, raça, condições sociais, preferências culturais, políticas, religiosas, e muito menos por estar na condição de portador de patologia ou deficiência.

É necessário, ainda, conhecer a especificidade de cada bairro e loco-região onde se irá atuar, considerando a conjuntura social global e propondo a criação de projetos que contemplem a demanda da população num contínuo processo de promoção social e humanização. 
Salientamos, para isso, elementos que comprovam a importância do profissional de Serviço Social de integrar a equipe de saúde do PSF e, juntamente com os demais profissionais, possibilitar recursos para a interação da população aos serviços públicos de saúde. Buscamos, em nossa análise, evitar o conhecimento limitado da proposta da Política de Educação Permanente dos que acreditam que se resume na promoção e participação em cursos de capacitação, especialização e aprimoramento, e, também, dos que abandonam a especificidade teórica e cientifica de cada intervenção profissional e, assim, acabam por resumir a referida proposta a um mero instrumento de revisão de práticas.

Assim, o compromisso com esses objetivos, podem direcionar a prática nos serviços de saúde, romper com a alienação trazida por modelos hegemônicos e papéis instituídos, tornando-nos, realmente, sujeitos dessas políticas sociais.

Foi essa a linha de ação adotada pelo Ministério da Saúde, pela Secretaria de Gestão do Trabalho e da Educação na Saúde, para instituir a Política Nacional de Educação Permanente em Saúde, tornando-se responsável pela proposição e formulação de políticas e ações. Entre elas, salientamos a formação, desenvolvimento e educação permanente dos trabalhadores de saúde em todos os níveis de escolaridade.

A Política de Educação Permanente, viável na medida em que é submetida a uma revisão constante (avaliação, coleta de resultados e nova avaliação), propõe, em um de seus princípios, a capacitação dos profissionais e trabalhadores da saúde para atuarem na dinâmica local dos problemas, ou seja, para que se voltem para a análise do contexto do seu bairro, comunidade ou município.

Na sequiência, houve a implantação dos Pólos de Educação Permanente em Saúde para o SUS, instâncias estas a se orientarem para a articulação na criação de novas ações e estratégias que promovam a educação permanente dos trabalhadores da saúde, fortaleçam a participação da sociedade civil no controle das políticas de saúde e qualifiquem a formação e atenção integral à saúde. Enfim, buscar, por meio da orientação e informação fornecidas à categoria de base da sociedade e até aos profissionais habilitados da saúde, alternativas para se pôr um fim ao tradicionalismo do setor da saúde que insiste em criar políticas públicas de caráter fragmentado:

[...] a saúde coletiva separada da clínica, qualidade da clínica independente da qualidade da gestão, gestão separada da atenção, atenção separada da vigilância, vigilância separada da proteção aos agravos internos e cada um desses fragmentos divididos em tantas áreas técnicas quanto sejam os campos de saber especializado. (CECCIM, 2004, p.161).

Essa é, pois, nossa forma de entender o compromisso com objetivos direcionados para uma prática mais humanizadora nos serviços de saúde. Parece-nos necessário, antes de qualquer coisa, romper com a alienação trazida por modelos hegemônicos e papéis instituídos, tornando-nos, realmente, sujeitos participantes da formulaçãoreformulação das políticas sociais.

\section{O Assistente Social como profissional da saúde}

É na questão da participação e fortalecimento da cidadania que o papel do Serviço Social na área da saúde se faz presente. Por meio da resolução $\mathrm{n}^{\circ} 218$ de 6 de março de 1997, o Conselho Nacional de Saúde reafirmou que o assistente social, entre outras categorias de nível superior, é também um profissional da área da saúde.

A atuação do assistente social nesta área dá-se como profissional comprometido com a produção da saúde dentro de parâmetros que valorizam as dimensões subjetivas e sociais do cidadão, observam princípios do projeto ético-político do Serviço Social e fortalecem o protagonismo dos sujeitos coletivos.

Com formação acadêmica apta à contextualização do indivíduo inserido em sua própria situação no ambiente, $o$ assistente social apresenta significativa contribuição à área da saúde, tendo em vista que a maioria das dificuldades enfrentadas advêm de fatores complexos como os políticos, econômicos, culturais e outros. 
Conforme Rossi (2004), dentre as atribuições do assistente social na área da saúde podem ser salientadas as seguintes:

- Ações de caráter emergencial: encaminhamentos para análise médica para a realização de exames, consultas, tratamentos, medicamentos, órteses, próteses, sangue, como também para a obtenção de transporte, alimento, roupa, abrigo, etc.

- Educação e informação em saúde: orientações e tratamentos individuais ou coletivo-grupais aos usuários, famílias ou comunidades para esclarecer, informar e buscar soluções acerca da problemática que envolve a colaboração destes na resolução de problemas de saúde.

- Planejamento e assessoria: local às unidades de saúde, especialmente em praticas de educação à saúde como a alimentação, a epidemiologia e sanitária. Instrumentalização dos processos de avaliação e controle das ações realizadas na unidade, bem como o fornecimento de informações sistematizadas sobre a operacionalização do sistema junto aos diretores, administradores, conselheiros da unidade e a própria comunidade. $\mathrm{O}$ treinamento, preparação e formação de recursos humanos representam atividades voltadas para a capacitação de funcionários, representantes comunitários, chefias intermediárias, etc.

- Mobilização da comunidade: consiste em ações educativas, voltadas para a sensibilização, politização e mobilização da comunidade em função da instalação e funcionamento dos conselhos.

Além disso, o profissional reúne os subsídios necessários para criar e coordenar programas dentro das unidades de saúde como os de controle de hipertensão, diabetes, hanseníase, acompanhamento do pré-natal, crianças recém-nascidas, idosos, portadores de deficiência. Participa das equipes interdisciplinares, empreendendo políticas sócioeducativas como as de esclarecimento e prevenção contra a AIDS e demais DSTs, planejamento familiar, sobre as drogas, hábitos de higiene. Realiza palestras, eventos e cursos junto à população. Realiza estudos sócio-econômicos com os usuários, a fim de buscar soluções nos órgãos públicos direta ou indiretamente ligados a determinado problema. Busca alternativas de enfrentamento dos problemas conforme a demanda, conciliando seus projetos com os recursos disponíveis na instituição a qual está inserido. Estimula a participação popular, incentivando a ampliação da consciência sanitária da comunidade.

Em sua atuação, o assistente social norteia-se por diretrizes que possam contribuir para a melhoria da qualidade dos atendimentos, como a ação interdisciplinar, a consciência sanitária e a participação dos usuários na instituição, por meio do controle dos serviços prestados.

E, para finalizar, podemos identificar a atuação do assistente social na área da saúde pelo desempenho ético-político dirigido à intervenção em aspectos sociais, econômicos e culturais relacionados ao processo saúde-doença, buscando formas de enfrentamento individual e coletivo para estas questões.

\section{O Assistente Social e sua incorporação à equipe mínima do PSF}

Enquanto membro da equipe de saúde da família, $o$ assistente social salienta-se como profissional que se dedica especialmente aos aspectos sociais e econômicos, que podem influenciar negativamente a saúde da família, a educação em saúde e a efetivação dos direitos da população. (MARTINS, 2002).

O profissional de Serviço Social atua como educador num trabalho de formação para a cidadania e organização política que oriente os usuários quanto aos seus direitos e os meios legais de reivindicá-los.

A formação também se realiza por meio de orientações e abordagens individuais ou coletivas acerca da participação dos usuários na resolução de problemas como epidemias e endemias, além de incentivá-los a participar dos Conselhos Municipais de Saúde como forma de se fazerem ouvidos e fazerem valer seus direitos. 
O profissional prioriza, ainda, o contato direto com os usuários, por meio do diálogo. Assim, insere-se na cultura destes, apreende os princípios que regem suas vidas e suas histórias, podendo, nessa abordagem integral, buscar em conjunto com os usuários, alternativas para seus problemas e de seus familiares.

Martins (2002), ao discorrer acerca da atuação do assistente social, refere que a ele cabe, também, "[...] elaborar, coordenar e executar treinamentos, bem como prestar supervisão e acompanhamento técnico a estagiários, profissionais e equipes ligadas ao PSF”. (MARTINS, 2002, p.54).

Já para Bettiol (2003, p.19-20), o profissional de Serviço Social pode, também, desenvolver atividades como:

\section{Articulação com a comunidade}

Consiste na identificação e aproximação com as lideranças dos bairros, ampliação das discussões sobre associativismo e assessoria aos trabalhos comunitários. Assessorar, incentivar e estimular a participação popular que, por inúmeros motivos, ainda não se uniu em associações para buscar a efetivação de seus direitos.

\section{Ações Comunitárias}

Compreende a busca de parcerias com entidades e órgãos do município (e até dos bairros) como igrejas, escolas e poder público, com o objetivo de articular atividades diversas que busquem melhor qualidade de vida da população, de acordo com a realidade e características locais de cada PSF. Dentre essas atividades, podemos citar a criação de projetos que estimulem a criatividade, a interação e a autovalorização dos usuários, grupos de apoio a alcoólatras e familiares, apoio a mulheres vítimas de violência doméstica, grupos para terceira idade, entre outros. Podem, ainda, ser criados fóruns de debates com a comunidade para orientações sobre o PSF, o processo de saúde e doença e o funcionamento do Conselho de Saúde.

\section{Capacitação em recursos humanos}

Refere-se ao planejamento de reuniões da equipe de saúde, capacitação para o trabalho em grupo, participação nos planejamentos e execução dos grupos, aplicação das diretrizes da Política de Educação Permanente para a promoção da saúde de forma mais humanizada.

\section{Integração e Intersetorialidade dos PSFs}

Consiste no planejamento de reuniões mensais com outras unidades de saúde da família e, posteriormente, com o gestor municipal de saúde para discussão do Programa, avaliação de seu desempenho e dos projetos e grupos desenvolvidos em cada unidade, bem como avaliar o processo de integração da saúde com as demais políticas públicas desenvolvidas no município.

Salientamos, ainda, o que nos parece de grande importância: como foi dito anteriormente, se a participação popular e o controle social fornecem elementos significativos para a efetivação e aperfeiçoamento do SUS, o assistente social poderá assumir o papel impulsionador e propositor de mudanças.

Inicie-se pelo atendimento básico, ao incluir todos os pacientes em projetos desenvolvidos no PSF, numa assistência de qualidade e, principalmente, de respeito, solidariedade e eqüidade. Em sequiência, o trabalho se encaminha no sentido de acabar com o estigma de "fazer do doente o culpado pela doença", e por outros tipos de problemas decorrentes de suas precárias condições de vida, que o fazem sentir-se inferiorizado e relutante em procurar ajuda.

Para o alcance desses objetivos de atuação, o assistente social realiza análise de conjuntura e planeja, juntamente com a população, condições mais apropriadas e dignas de vida, que acabem com a situação de exploração das classes menos favorecidas.

$\mathrm{O}$ assistente social contribui, ainda, para a formação de uma consciência crítica, incentivando a população a reivindicar seus direitos, denunciar o desrespeito e a indiferença no atendimento aos órgãos responsáveis como os Conselhos de Saúde. Com isso, busca-se incentivar os usuários a exercerem a 
cidadania e exporem idéias e sugestões para melhorar $o$ atendimento no PSF.

Nossa intenção, aqui, é caracterizar a equipe de saúde em conjunto com o trabalho do assistente social, como fundamental para o processo de humanização do atendimento à saúde no nível básico, mais especificamente, no PSF.

\section{Considerações Finais}

A implantação do SUS foi apresentada, neste artigo, como "política de inclusão" que tem recorrido a constantes revisões e propostas estratégicas em busca da coerência com as necessidades apontadas na área da saúde da população brasileira, que tem ramificações e determinantes na questão social e na forma como a sociedade vive e articula recursos que a possibilitem viver. Vencer as doenças que acometem a população brasileira pode ser uma meta de muitos caminhos e talvez o mais importante de todos seja o da prevenção, buscando-se conservar a saúde conforme a realidade e necessidade do país. Esta posição abre um leque muito grande de responsabilidades para uma só área, pois ao abranger educação, habitação, alimentação, meio ambiente e outros aspectos com que se reveste a questão social, não é possível que seja decidido por um só elemento hegemônico do jogo político, que delega todas as ações à saúde publica e a seus profissionais. Dentre as medidas e estratégias buscadas para o encaminhamento da Política Nacional de Saúde, temos o PSF aqui discutido como o espaço propício para a elaboração de uma proposta de trabalho pioneira acerca da implantação das ações da Política de Educação Permanente na prestação de seus serviços, na busca por um atendimento de acolhimento total do usuário. Dentro da idéia de humanização, a estratégia de Educação Permanente possibilitaria a superação do atendimento de caráter curativo, da busca pelo pronto-atendimento e da crença quase absolutista no modelo hospitalocêntrico e no médico especialista, o que tornaria possível superar este que é um dos maiores impasses verificados na implantação definitiva da filosofia do PSF. De fato, a intenção de se adotar a visão comunitária de saúde como predominante precisa ser revista a partir de necessidades regionais e um maior conhecimento dessa Política, em princípio, por parte das equipes de saúde do PSF. Deve haver também o incentivo à participação popular, o controle social, a integração entre as políticas públicas municipais e a percepção do indivíduo como um todo, evitando-se a idéia conservadora do saber e do diagnóstico fragmentado.

A concretização de projetos como este enfrenta obstáculos políticos. O controle social incomoda, exige idoneidade do poder público, fiscaliza suas ações, condena atos ilícitos. Ao se permitir e incentivar a população sair da condição de alienação para se organizar e lutar pelo direito a um atendimento mais humanizado num serviço de saúde que lhe é legalmente garantido, outras questões são levantadas. Entre elas, a efetividade de funcionamento dos Pólos de Educação Permanente, a atenção ao preparo e capacitação dos profissionais envolvendo cargas horárias justas e salários dignos, condições de trabalho e de vida adequadas às necessidades e expectativas do corpo de servidores, e assim por diante. Como nada disso é atendido, despertar a fúria oprimida dos direitos não atendidos não só vem piorar o atendimento na área da saúde, até porque ao se jogar toda a incompetência administrativa secular em cima de um servidor da área só vai adoecê-lo, e em lugar de saúde, teremos espalhado mais doença, como uma nova epidemia.

O princípio da prevenção, além de trazer benefícios para a população usuária, reduz o número de internações e alivia o déficit do SUS provocado pela necessidade de empenhar uma verba vultosa em medicina curativa. Há aí interessante paradoxo, quando a medicina curativa pode inviabilizar a prevenção, aumentando circularmente sempre os seus custos para a própria população doente e a sociedade em geral, através de impostos ou mesmo por meio das cobranças da "porta dupla de entrada no sistema de saúde", ou seja, das altas taxas cobradas pelos convênios médicos. 
A introdução da Política de Educação Permanente no PSF visa a criar condições de diálogo e participação entre a própria equipe de saúde, que por meio das trocas de saberes e práticas, ampliaria o universo de compreensão do usuário como integrante de um contexto socioeconômico, político e cultural e proporcionaria, dessa forma, um trabalho de prevenção e instrução do mesmo, conforme os propósitos do programa.

Os usuários, por sua vez, ao serem consultados, demonstram falta de conhecimento dos objetivos do programa e manifestam muitas dúvidas não esclarecidas. Todavia, o programa é parte de uma política de saúde que elimina os princípios do poder verticalizado. Ele é proposto pelo governo, mas é pensado, adaptado e implantado conforme o contexto e a demanda de cada município e cada micro área de atendimento, no processo democrático. A população, incentivada a tomar parte nesse processo de integração, engajada num propósito, tem seu interesse na melhoria de sua qualidade de vida despertado a partir do entendimento da dinâmica do PSF, da participação em grupos sócio-educativos e da apresentação de críticas e propostas que possam aprimorar o atendimento.

Analisamos o processo de pensar o indivíduo como um todo, aceitando a saúde e a qualidade de vida como um conjunto de fatores que envolvem o trabalho e o suporte de outras políticas públicas num procedimento chamado intersetorialidade.

Contudo, observamos que tal procedimento requer tempo, investimento e interesse político para se efetuar. Parte do princípio que os trabalhadores comprometidos com a dignidade do ser humano na garantia dos chamados mínimos sociais, ao empenharse na concretização deste projeto, possibilitam melhores condições de vida para os habitantes de cada município e, conseqüentemente, sua inclusão social.

Baseados nessa finalidade é que apresentamos como proposta a adição do assistente social como integrante da equipe básica de saúde da família, pela contribuição que a categoria profissional pode imprimir na prática da Política de Educação Permanente em Saúde. Fundamentamos nossa proposta no princípio de que o assistente social, enquanto integrante da equipe de saúde, é o profissional qualificado para identificar as necessidades do usuário, bem como as condições sociais às quais está inserido. Apoiado na visão de totalidade, pode alavancar as ações da equipe interdisciplinar destacando aspectos relevantes no âmbito social, disponibilizar recursos e propor mudanças. O Serviço Social, enquanto profissão, reúne condições de empreender uma política social educativa de enfrentamento da questão social na área da saúde.

Face ao que foi exposto e ao reafirmar as diretrizes do SUS e a Política de Educação Permanente como ação interdisciplinar que possibilita um atendimento mais humanizado na saúde pública, parece-nos importante recomendar a ampliação da equipe do PSF por meio da inserção do assistente social enquanto profissional de saúde. Referimo-nos especialmente a sua formação de cunho humanista, comprometida com valores que dignificam e respeitam os seres humanos em suas diferenças e potencialidades e contribuem, significativamente, para a democratização do acesso e universalização dos serviços de saúde. Esses valores, aliás, são os enfatizados pelo projeto ético-político e profissional do Serviço Social, que o legitima em sua luta pela liberdade, justiça e democracia.

\section{Referências}

BETTIOL, L. M. O Programa de Saúde da Família, a participação popular e a Atenção Básica: a experiência da Estância Turística de Santa Fé do Sul. 2003. Dissertação (Mestrado em Serviço Social) - Faculdade de História, Direito e Serviço Social, Universidade Estadual Paulista, Franca.

BRASIL. Ministério da Saúde. Sistema Único de Saúde. Conselho de Saúde: guia de referências para sua criação e organização. Brasília, DF: Ministério da Saúde, 1993.

BRASIL. Constituição (1988). Constituição da República Federativa do Brasil: promulgada em 5 de outubro de 1988. 4.ed. São Paulo: Saraiva, 1990. (Série Legislação Brasileira). 
BRASIL. Ministério da Saúde. Institui a Política Nacional de Educação Permanente em Saúde como estratégia do Sistema Único de Saúde para a formação e/ou desenvolvimento de trabalhadores para o setor e dá outras providências. Portaria n. 198/GM/MS, de 13 de fevereiro de 2004. Disponível em: <http://www.saude.sc.gov.br/ publicacoes/gedrhus/polosfinal_pactuado_tripartite.doc $>$. Acesso em: 19 jun. 2005

BRASIL. Ministério da Saúde. Ministério da saúde lança política de humanização do SUS, 2004. Disponível em: <http://www.amb.org.br/inst=notícias_amb_template.php3>. Acesso em: 27 jul. 2004.

BRASIL. Ministério da Saúde. Norma Operacional Básica do Sistema Único de Saúde/NOB - SUS 96. Brasília: Ministério da Saúde, 1997.

BRASIL. Ministério da Saúde. Política de educação e desenvolvimento para o SUS. Disponível em: <http:// www.saude.sc.gov.br/publicacoes/gedrhus/ polosfinal_pactuado_tripartite.doc>. Acesso em: 19 jul. 2005.

CARVALHO, G. I.; SANTOS, L. Sistema Único de Saúde: comentários à Lei Orgânica da Saúde (Leis n. 8.080/90 e n.8.142/90). 3.ed. Campinas: Unicamp, 2001.

CECCIM, R. B. Educação permanente em saúde: desafio ambicioso e necessário. Interface: comunicação, Botucatu, v.9, n.16, p.161-77, set. 2004. Disponível em:<http:// www.interface.org.br/revista16/debate1.pdf >. Acesso em: 16 fev. 2005.

CONFERÊNCIA NACIONALDESAÚDE, 8., 1986, Brasília. Relatório ... Brasília: Ministério da Saúde, 1987.

CONFERÊNCIA NACIONAL DESAÚDE, 9., 1992, Brasília. Relatório ... Brasília: Ministério da Saúde, 1993.

CONFERÊNCIA NACIONAL DE SAÚDE, 10., 1996, Brasília. Relatório ... Brasília: Ministério da Saúde, 1998.

CONFERÊNCIA NACIONAL DE SAÚDE, 11., 2000, Brasília. Relatório ... Brasília: Ministério da Saúde, 2002.
CONFERÊNCIA NACIONAL DE SAÚDE. 12., 2003, Brasília. Relatório... Brasília: Ministério da Saúde, 2004.

FREIRE, P. Pedagogia do oprimido. 6.ed. Rio de Janeiro: Paz e Terra, 1978.

MARTINS, J. A. Programa de Saúde da Família: um novo desafio para o Serviço Social. 2002. Trabalho de Conclusão de Curso (Graduação em Serviço Social) - Faculdade de História, Direito e Serviço Social, Universidade Estadual Paulista, Franca.

MATIUZO, A.; GALLO, R. UBDS central adota atendimento relâmpago. Folha de São Paulo, São Paulo, 17 maio 2004. Folha Ribeirão. p.C1.

MONITORIA E AVALIAÇÃO DOS PROCESSOS DE REFORMA DO SETOR DA SAÚDE. Disponível em: <http://www.paho.org/portuguese/gov/ce/ce124_17.pdf >. Acesso em: 15 ago. 2005.

NEGRI, B. A política de saúde no Brasil, nos anos 1990: avanços e limites. In: NEGRI, B.; VIANA, A. (Org.). $O$ Sistema Único de Saúde em dez anos de desafio. São Paulo: Sobravine/ Cealag, 2002.

ROSSI, A. S. Programa de saúde da família: um enfoque no social. 2004. Trabalho de Conclusão de Curso (Graduação em Serviço Social) - Faculdade de História, Direito e Serviço Social, Universidade Estadual Paulista, Franca.

SALAZAR, A.; RODRIGUES, K. G.; SILVER, L.; SCHEFFER, M. (Org.). O SUS pode ser seu melhor plano de saúde. São Paulo: IDEC, 2003.

SOUZA, H. M. de. Saúde da família: desafios e conquistas. In: NEGRI, B.; VIANA, A L. A (Org.). O sistema único de saúde em dez anos de desafio. São Paulo: Sobravime/ Celag, 2002.

SPOSATI, A; LOBO, E. Controle social e políticas de saúde. Cadernos de Saúde Pública, Rio de Janeiro, n.8, p.366-378, out./dez, 1992. 
